\title{
Fabrication of High Efficient Dye Sensitized Solar Cell Using Eosin Blue Sensitizer
}

\author{
K.R.M.Vijaya Chandrakala ${ }^{1}$, K. Ravi Teja ${ }^{1}$, N. Sandeep Kumar ${ }^{1}$, P. Vivek Phani \\ Raghavendra $^{1}$, and LNV Sai Bhaskar Majji ${ }^{1}$ \\ ${ }^{1}$ Department of Electrical and Electronics Engineering, Amrita School of Engineering, \\ Coimbatore, Amrita Vishwa Vidyapeetham, Amrita University, India. \\ krm_vijaya@cb.amrita.edu
}

\begin{abstract}
For past several decades research in the field of photovoltaic has progressed from first generation solar cell to third generation solar cell. The dominance of solid state device which converts photons to electrons is a new challenge in technologies. In this work, a high efficient Dye Sensitized Solar Cell (DSSC) is fabricated. DSSC is easy to fabricate solar cell among the conventional pn-junction photo voltaic solar cells and even it is eco-friendly. A typical DSSC suffers from semiconductor liquid junctions and therefore concerns of electrolyte volatility and breakdown persists. By optimizing the sintering time, temperature, proper choosing of different types of sensitizer/dyes and the electrolyte, improves the efficiency of DSSC. It focuses towards developing DSSC on a small scale with the glass plates as electrodes coated with Titanium Oxide $\left(\mathrm{TiO}_{2}\right)$ and graphite. The plates are conducting which are coated with Fluorine doped Tin Oxide (FTO). To enhance the absorption power of the glass plates Eosin blue is chosen as a dye. These electrodes are placed in an electrolyte made up of Lithium Iodide (LiI) and Iodine (I). The electrical conduction mechanism of the fabricated DSSC is studied at 50 lux and also tested with cascaded series cell connection.
\end{abstract}

Keyword: Working electrode; Counter electrode; Titanium Oxide $\left(\mathrm{TiO}_{2}\right)$; Eosin blue dye; Electrolyte

\section{Introduction}

In the last two decades the need for solar energy has increased. The photovoltaic market is still dominated by traditional solid-state pn junction devices, usually made from crystalline or amorphous silicon. Although the cost per watt of silicon solar cells has dropped significantly over the past decade, these devices are still expensive to compete with conventional grid electricity. It is an urgent task to develop much cheaper photovoltaic devices with reasonable efficiency for widespread application of photovoltaic technology. In this context, a new type of photovoltaic devices called "dye sensitized solar cells"(DSSCs) based on nanocrystalline $\mathrm{TiO}_{2}$ was developed by O'Regan and Grätzel in 1991. This type of solar cells is featured by their relatively high efficiency (exceeding $11 \%$ at full sunlight) and low fabrication cost $\left(1 / 10^{\text {th }}\right.$ to $1 / 5^{\text {th }}$ of silicon solar cells). Since the birth of DSSCs, great efforts have been devoted in making these devices more efficient and stable. Long-term stability tests show good prospect of DSSCs for domestic devices and decorative applications in this century. Out of all solar energy resources, DSSC had gathered a great attention in the present world for its eco-friendly benefits. Due to the concept of wide band gap semi-conductors, DSSC existence had taken place in 1960 [1-3]. DSSC is also called as GRATZEL, cell named after its co-inventor. The reason for choosing DSSC is because of its good price and performance ratio, low cost, ability to work at wider angles, low light, long life, mechanical robustness and ability to work at low internal temperatures.

The basic idea of a solar cell is to convert light energy into electrical energy. The energy of light is transmitted by photons, small packets or quantum of light. Electrical energy is stored in electromagnetic fields which in turn can make a current of electrons flow. Thus in a solar cell flow of photons correspond to a flow of electrons. DSSC is an electro-chemical solar cell which consists of four basic elements namely; Transparent conducting oxide electrodes, 
Sensitizer, Semi conducting layer, Electrolyte. In earlier stages of DSSC, the semi conducting layers used are Zinc Oxide $(\mathrm{ZnO})$ and Tin Oxide $\left(\mathrm{SnO}_{2}\right)$ whose efficiency is proved to be lesser than 6\% [4-7]. The breakthrough had come in 1991 by using Titanium dioxide $\left(\mathrm{TiO}_{2}\right)$ as semi conducting layer which was found to be higher than $7 \%$ efficiency using a Ruthenium sensitizer as a base [8].

The dye sensitized solar cells are made up of low cost materials and are cheaper to manufacture. These solar cells do not require any apparatus and can be printed on any flexible surface. Due to the reduced manufacturing costs, these solar cells are less expensive when compared to other semiconductor cells [9-10]. The dye used in dye sensitized solar cells can absorb diffused sunlight and fluorescent light. DSSC's also works in cloudy weather and low light conditions without much impact on the efficiency while other traditional cells would fail at illumination below a certain range. Dye sensitized solar cells have a lower cut off. This makes them suitable for running small devices indoor. These solar cells also work at wider angles, a fact which makes these cells absorb most of the available sunlight. As the temperature rises, some electrons in semiconductors are pushed to conduction band mechanically. Hence, the silicon cells require the protection by covering in a glass box. Such cells get heated easily and hence the efficiency is greatly reduced due to internal temperature. This situation is eliminated in the Dye sensitized solar cells (DSSC).

As, dye sensitized solar cells are made of only a thin layer of plastic, heat radiates away easily to reduce the internal temperature. This lowering of temperature in turn helps in increasing the efficiency of solar cells [11-14].

In this work, a Dye sensitized solar cell is fabricated in a systematic way and various electrical parameters of solar panel is measured such as open circuit voltage, short circuit current, maximum power output, fill factor and efficiency. Therefore, in DSSC as electrodes FTO glass plates is being coated with the dye and sensitizer developed placed in $\mathrm{TiO}_{2}$ electrolyte is fabricated whose discussion is followed in subsequent sections.

\section{Working Principle of Dye Sensitized Solar Cell (DSSC)}

Dye sensitized solar cells (DSSC) mainly has a photo anode, counter electrode, electrolyte and Dye [1-3]. The photo anode is a FTO glass plate coated with TiO2 nano-particles on which eosin blue dye is coated. The photo excitation of dye results in injection of electrons into the conduction band of semiconductor. The energy transfer of DSSC is shown in Figure 1.

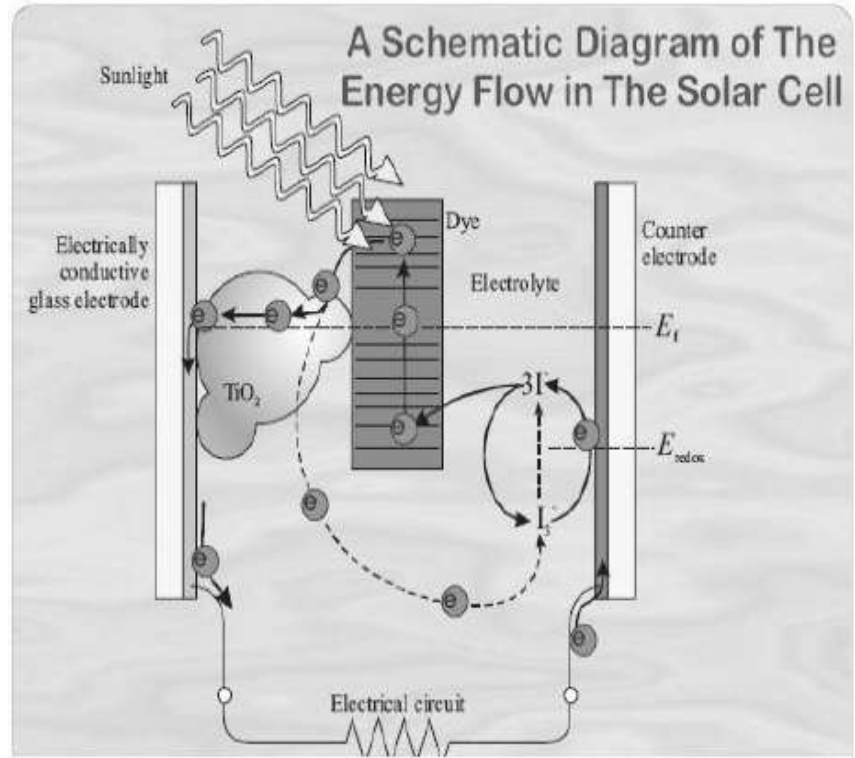

Figure.1 Schematic Diagram of Energy flow in DSSC 
In this, whenever a light is incident on dye, an electron is excited from lower energy band to higher energy band. This energy is used to travel through $\mathrm{TiO}_{2}$ layer. The electron from $\mathrm{TiO}_{2}$ is taken by transparent conducting electrodes through load. This electron in turn is regained to dye via electrolyte, thus, forms a closed circuit.

There are two reactions in a dye sensitized solar cell namely, recombination of conduction band electrons with oxidized dye which occurs in a microsecond scale and the recombination of conduction band electrons with Iodine in electrolyte.

Open circuit voltage (Voc) across the cell is the potential developed across load when current through the device is zero and it is expressed as in equation (1),

$$
V_{O C}=\left(\frac{n K T}{q}\right) \cdot\left[\ln \left(\frac{I_{s c}}{I_{o}}\right)+1\right]
$$

Where; ' $\mathrm{n}$ ' is the number of electrons; ' $\mathrm{T}$ ' is the temperature in ${ }^{\circ} \mathrm{C}$; ' $\mathrm{K}$ ' $=$ Boltzmann constant and ' $\mathrm{q}$ ' is the charge in C.

The power is obtained by multiplying ' $\mathrm{V}$ ' and ' $\mathrm{I}$ ' at different loads. The I-V graph is plotted and peak of the graph corresponds to maximum power which is represented in equation (2);

$$
P_{\max }=V_{\max } . I_{\max }
$$

The Fill Factor (FF) being essentially a measure of the quality of the solar cell, it is the ratio of maximum power output referring to equation (2) to the product of the open circuit voltage and short circuit current is expressed in equation (3);

$$
F F=\left(\frac{V_{\max } \cdot I_{\max }}{V_{o c} \cdot I_{s c}}\right)
$$

The efficiency of the solar cell which determines utmost the reliability of the panel is defined as the ratio of electrical energy output to light energy input which is represented in equation (4);

$$
\text { Efficiency }=\left(\frac{\text { Vmax.Imax }}{P_{\text {in }} \cdot A}\right)
$$

Where; ' $P_{\text {in }}$ ' is the identical optical power in Watts and ' $A$ ' is the illuminated area in $\mathrm{cm}^{2}$.

\section{Fabrication of Dye Sensitized Solar Cell (DSSC)}

The main components involved in a DSSC are working electrode which is anode or working electrode, counter electrode which is cathode, electrolyte and the sensitizer. The working electrode or anode is made up of $\mathrm{TiO}_{2}$ paste and counter electrode is made up of graphite. The electrolyte used is a mixture of Lithium Iodide and Iodine and the dye is made from Eosin Blue extract. The dye enhances the absorption power of the glass plates. The working and counter electrodes are placed such that they are facing each other and electrolyte is inserted between them.

The process involved in the fabrication of DSSC is firstly; to prepare $\mathrm{TiO}_{2}$ paste and uniformly coat on to one of the Fluorine doped Tin oxide (FTO) plate to fabricate working electrode or anode. The FTO glass plates are cleaned using distilled water and acetone so as to remove any dust particles and unnecessary depositions on it. The $\mathrm{TiO}_{2}$ paste is prepared by 
mixing 3.5grams of $\mathrm{TiO}_{2}$ nano-particles to $15 \mathrm{ml}$ of ethanol. The mixture is then sonicated for $45 \mathrm{~min}$ in the sonicater which is shown in Figure 2.

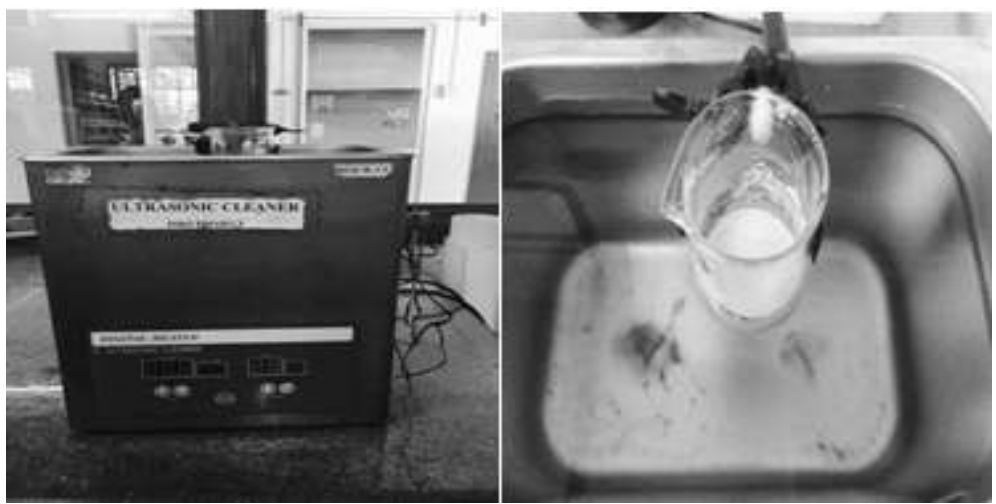

Figure 2. $\mathrm{TiO}_{2}$ paste in sonicator

A thin paste is obtained from this process that can be applied on one of the FTO glass plate by doctor blade technique [12].The coating of this paste is done for 4 or 5 layers such that the paste gets adhered onto the FTO glass plate tightly. The coated glass plate is now sintered in a muffle furnace at a temperature of $450^{\circ} \mathrm{C}$ for 30 minutes and the sintered glass plates are immersed in the solution of Eosin Blue dye.

One of the main reasons to choose eosin blue over other synthetic dyes is that it yields maximum power output when compared to other synthetic dyes. The property or sensitivity of eosin blue sensitizer is compared w.r.t other synthetic dyes is shown in Table 1 [15].

Table 1. Comparison of eosin blue parameters w.r.t different synthetic dyes [15].

\begin{tabular}{llllllll}
\hline Dye & $\lambda_{\max }[\mathrm{nm}]$ & $J_{\mathrm{sc}}\left[\mathrm{mA} / \mathrm{cm}^{2}\right]$ & $V_{\mathrm{oc}}[\mathrm{V}]$ & $J_{m}\left[\mathrm{~mA} / \mathrm{cm}^{2}\right]$ & $V_{m}[\mathrm{~V}]$ & $F F$ & $\eta[\%]$ \\
\hline Eosin Y & 520 & 1.020 & 0.671 & 0.787 & 0.509 & 0.581 & 0.399 \\
Aniline blue & 625 & 0.505 & 0.630 & 0.410 & 0.438 & 0.564 & 0.117 \\
Bromophenol blue & 426 & 0.513 & 0.549 & 0.350 & 0.337 & 0.479 & 0.120 \\
Alcian blue & 624,672 & 0.470 & 0.600 & 0.358 & 0.483 & 0.556 & 0.156 \\
Methyl orange & 651 & 0.500 & 0.549 & 0.341 & 0.341 & 0.424 & 0.115 \\
Crystal violet & 588 & 0.839 & 0.566 & 0.665 & 0.377 & 0.526 & 0.249 \\
Fast green & 620 & 0.374 & 0.600 & 0.288 & 0.416 & 0.533 & 0.117 \\
Carbol fuchsin & 550 & 0.841 & 0.608 & 0.700 & 0.436 & 0.596 & 0.303
\end{tabular}

Where; Eosin (A), bromophenol blue (B), aniline blue (C), alcian blue (D), methyl orange (E), crystal violet $(\mathrm{F})$, fast green $(\mathrm{G})$, and carbol fuchsin $(\mathrm{H})$.

The power characteristics of Eosin Blue (A) w.r.t other synthetic dyes i.e. (B,C,D,E,F,G and $\mathrm{H})$ mentioned in Table 1 is plotted between current density ' $\mathrm{J}$ ' $\left(\mathrm{mA} / \mathrm{cm}^{2}\right)$ for different values of applied voltage ' $\mathrm{V}$ ' which is shown in Figure 3 [15]. DSSC output power is calculated as $\mathrm{P}=\mathrm{JV}$ using the $\mathrm{J}-\mathrm{V}$ data shown in Figure 3. 


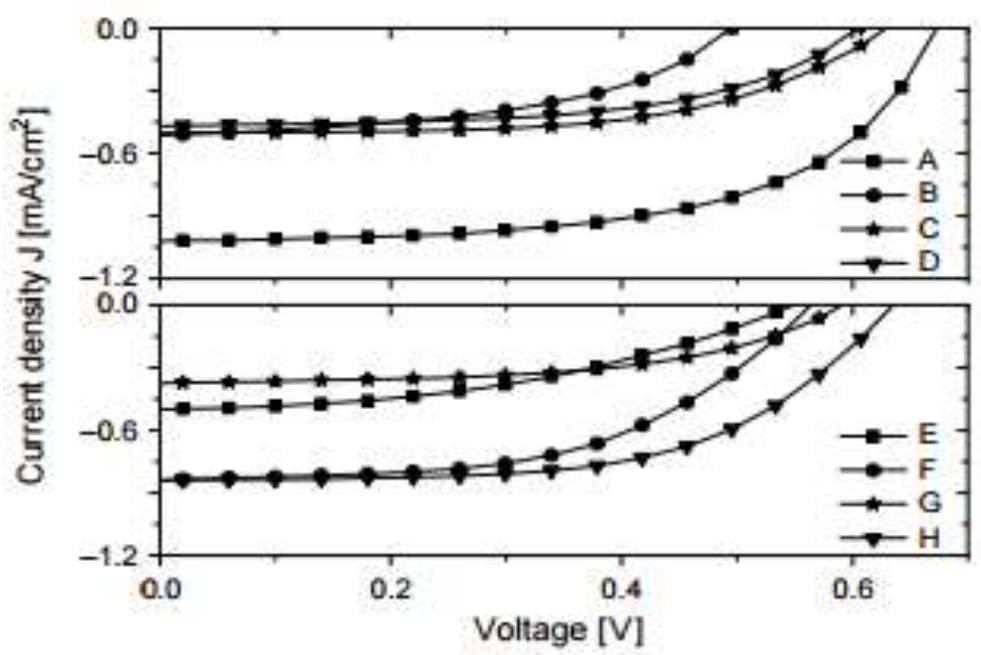

Figure 3. Current density versus voltage of eosin blue compared with other synthetic dyes[15]

Referring to Table 1 , the short circuit current density $\left(\mathrm{J}\right.$ in $\left.\mathrm{mA} / \mathrm{cm}^{2}\right)$ and open circuit voltage (Voc in V) has a maximum value of $1.020 \mathrm{~mA} / \mathrm{cm}^{2}$ and $0.671 \mathrm{~V}$ respectively for the DSSC sensitized with the eosin blue when compared to other synthetic dyes. The highest output power and efficiency were obtained for the DSSC sensitized with eosin blue whose efficiency of the cell claims to be $0.399 \%$ [15]. Hence; eosin blue is the best synthetic dye and efficient sensitizer used for the proposed solar cell to fabricate.

Further, the FTO coated glass plate is carried through annealing process, in which, the glass plates in the muffle furnace at $200^{\circ} \mathrm{C}, 300^{\circ} \mathrm{C}, 400 \stackrel{\circ}{\mathrm{C}}$ and $450 \stackrel{\circ}{\mathrm{C}}$ for grain size cells shown in Figure 4.

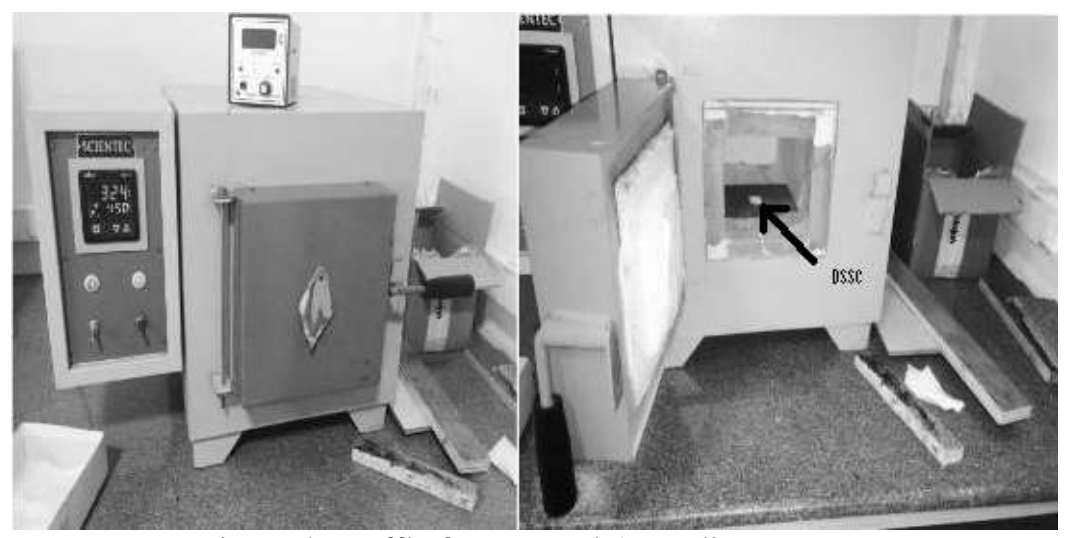

Figure 4. Muffle furnace and Annealing Process

At optimal temperature of $450{ }^{\circ} \mathrm{C}$ for $30 \mathrm{~min}$, series combination of two cells is tested. Secondly, proceed preparing the sensitizer or dye. The light harvesting efficiency and hence the conversion efficiency depends on the properties of the sensitizer used. The sensitizer or the dye is prepared by adding $14 \mathrm{mg}$ of Eosin Blue dye particles into $20 \mathrm{ml}$ of ethanol along with $15 \mathrm{ml}$ of acetonitrile. The sintered glass plate obtained from the above step is immersed in this dye solution for 48 hours so that the dye gets covalently bonded onto the surface of the anode. The properties of the electrolyte also have great effect on the conversion efficiency and stability of the cell. Therefore, an electrolyte prepared is of $330 \mathrm{mg}$ of Lithium Idodide (LiI) and $33 \mathrm{mg}$ of Iodine (I) in $5 \mathrm{ml}$ of acetonitrile. The counter electrode is made up of graphite which is sketched with pencil on the glass plates as shown in Figure 5. 


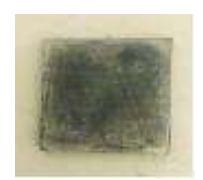

Figure 5. Counter Electrode

Artificial graphite has the features of high temperature strength, Good thermal and electrical conductivity and Low thermal expansion as that of river sand [16]. Finally, all the above prepared components are assembled to prepare the cell. The $\mathrm{TiO}_{2}$ coated electrode plate is dipped in the dye/sensitizer for about 48 hours. Then, the counter electrode or the graphite coated plate is prepared by shading with pencil on a glass plate. Both the electrode and counter electrode are hold together facing each other by the binder clips. The electrolyte is then filled in between them with the help of a ink filler, thus forming complete Dye Sensitized Solar Cell. The fabricated DSSC cell is shown in Figure 6.

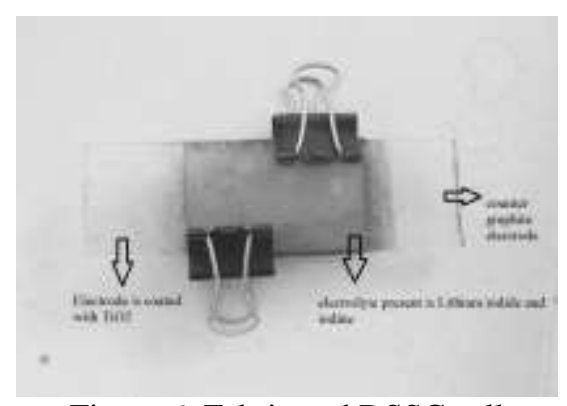

Figure 6. Fabricated DSSC cell

\section{Experimental Results}

The fabricated cell is exposed to light of 50 lux and its efficiency and quality of the cell is notified in the following section.

A. Single DSSC cell exposed to light of 50 lux

Table 2. Single DSSC output power at 50 lux

\begin{tabular}{llll}
\hline $\begin{array}{l}\text { Resistance } \\
(\mathrm{ohms})\end{array}$ & $\begin{array}{l}\text { Current } \\
(\mathrm{uA})\end{array}$ & Voltage $(\mathrm{mV})$ & $\begin{array}{l}\text { Power } \\
(\mathrm{nW})\end{array}$ \\
\hline 200 & 56.4 & 14.8 & 834.72 \\
\hline 400 & 54.5 & 28.6 & 1558.7 \\
\hline 600 & 52.7 & 41.5 & 2187.05 \\
\hline 800 & 51.2 & 54.9 & 2810.88 \\
\hline 1000 & 49 & 66.3 & 3248.7 \\
\hline 1200 & 47.9 & 75.5 & 3616.5 \\
\hline 1400 & 46.6 & 86 & 4007.6 \\
\hline 1600 & 45.1 & 95.1 & 4289.01 \\
\hline 1800 & 44 & 104.1 & 4580.4 \\
\hline 2000 & 42.6 & 112.7 & 4801.02 \\
\hline 4000 & 39.3 & 155 & 6091.5 \\
\hline 5000 & 36.4 & 191.3 & 6963.2 \\
\hline 10000 & 33.6 & 222 & 7459.2 \\
\hline 15000 & 25.5 & 335 & 8542.5 \\
\hline 20000 & 20.8 & 410 & 8528 \\
\hline & 17.6 & 460 & 8096 \\
\hline
\end{tabular}


The first trial was carried out with a solar cell of $4.65 \mathrm{~cm}^{2}$ dimension illuminated with a light intensity of 50 lux. The cell produced an output with an open circuit voltage ' $\mathrm{V}_{\text {oc }}$ ' of $728 \mathrm{mV}$ and short circuit current ' $\mathrm{I}_{\mathrm{sc}}$ ' of $58.6 \mu \mathrm{A}$. On varying the load across the DSSC, the power ' $\mathrm{P}$ ' in $\mathrm{nW}$ was observed and tabulated in Table 2.

From the Table 2, it shows that at $10,000 \mathrm{ohms}$ of load the maximum output power across the DSSC at 50 lux is $8542.5 \mathrm{nW}$. Figure 7 shows the experimental set up of single DSSC cell connected to $10000 \mathrm{ohms}$ of resistive load. Using equation (3), the fill factor of the DSSC cell is 0.2. And, using equation (4), the maximum efficiency of the DSSC at minimum optical power ' $\mathrm{P}_{\mathrm{in}}$ ' of $0.0395 \mathrm{~mW} / \mathrm{cm}^{2}$ illuminated with 50 lux on $4.65 \mathrm{~cm}^{2}$ area is $4.65 \%$.

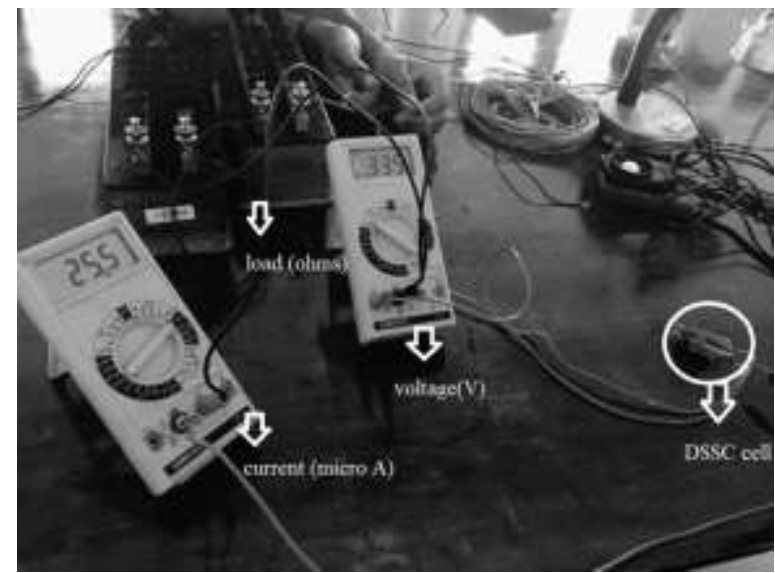

Figure 7. Experimental setup of a single DSSC at 50 lux

B. Series combination of two DSSC cell exposed to light of 50 lux

The performance of the single DSSC cell has given predominant efficiency and justifiable quality, therefore, two DSSC cells were fabricated in series check its feasibility in terms of efficiency and fill factor. With the same dimension of one solar cell of area $4.65 \mathrm{~cm}^{2}$ is combined in series with the same area of dimension of another DSSC and exposed to light intensity of 50 lux. The two series combination of DSSC cell produced an open circuit voltage ' $\mathrm{V}_{\mathrm{oc}}$ ' of $932 \mathrm{mV}$ and short circuit current of $35.9 \mu \mathrm{A}$ is shown in experimental setup Figure 8.

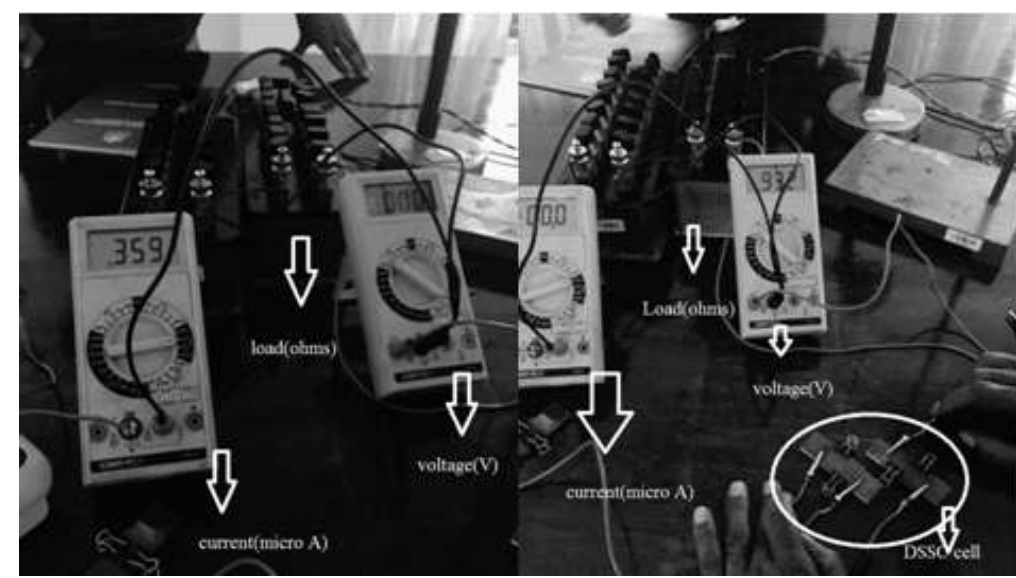

Figure 8. Experimental setup of series combination of two DSSC at 50 lux

On varying the load across the DSSC, the power ' $\mathrm{P}$ ' in $\mathrm{nW}$ was observed and tabulated in Table 3 . 
Table 3. Output power across two series DSSC at 50 lux

\begin{tabular}{llll}
\hline $\begin{array}{l}\text { Resistance } \\
(\mathrm{ohms})\end{array}$ & $\begin{array}{l}\text { Current } \\
(\mu \mathrm{A})\end{array}$ & $\begin{array}{l}\text { Voltage } \\
(\mathrm{mV})\end{array}$ & $\begin{array}{l}\text { Power } \\
(\mathrm{nW})\end{array}$ \\
\hline 500 & 179 & 121.5 & 21748.5 \\
\hline 1000 & 156 & 200 & 31200 \\
\hline 1500 & 130.3 & 248 & 32314.4 \\
\hline 2000 & 110 & 277 & 30470 \\
\hline 3000 & 81.1 & 333 & 29337.3 \\
\hline 4000 & 74.2 & 363 & 26934.6 \\
\hline 5000 & 61.5 & 384 & 23616 \\
\hline 6000 & 53.6 & 403 & 21600.8 \\
\hline 10000 & 35.1 & 438 & 15373.8 \\
\hline 15000 & 25.6 & 479 & 12262.4 \\
\hline 20000 & 19.7 & 587 & 11563.9 \\
\hline
\end{tabular}

From the Table 3, it shows that at 1500 ohms of load the maximum output power across two series combined DSSC at 50 lux is $32314.4 \mathrm{nW}$. Figure 9 shows the experimental set up of two DSSC cell connected in series to $1500 \mathrm{ohms}$ of resistive load. Using equation (3), the fill factor of the DSSC cell is 0.9658. And, using equation (4), the maximum efficiency of the DSSC at minimum optical power ' $P_{\text {in }}$ ' of $0.0395 \mathrm{~mW} / \mathrm{cm}^{2}$ illuminated with 50 lux on $4.65 \mathrm{~cm}^{2}$ area across two cells in series is $8.81 \%$. Table 4 consolidates the performance in terms of efficiency and fill factor of the fabricated single DSSC and series combination of two DSSC.

Table 4. Performance of DSSC illuminated at 50 lux

\begin{tabular}{lcccc}
\hline Illuminated at 50 lux & Voc $(\mathrm{mV})$ & Isc $(\mu \mathrm{A})$ & Efficiency $(\%)$ & Fill Factor \\
\hline Single DSSC cell & 728 & 58.6 & 4.65 & 0.2 \\
\hline Two DSSC cell in series & 932 & 35.9 & 8.81 & 0.9654 \\
\hline
\end{tabular}

The efficiency and fill factor of the fabricated DSSC is predominantly good value to prove its establishment for higher level of voltage production through cascading cells in series. For further future work optimal sizing of the solar cell could be focused using soft computing techniques [17].

\section{Conclusion}

A high efficient Dye Sensitized Solar Cell (DSSC) was fabricated on a small scale basis and its performance on varying loads was experimentally verified. The choice of electrodes, dye and electrolyte were chosen and prepared which are cheap and eco-friendly in nature. The glass plates as electrodes were coated with Titanium Oxide $\left(\mathrm{TiO}_{2}\right)$ on working electrode and graphite on counter electrode. The electrodes are conducting glass plates coated with Fluorine doped Tin Oxide (FTO). To enhance the absorption power of the glass plates Eosin blue is chosen as a dye. These electrodes are placed in an electrolyte made up of Lithium Iodide (LiI) and Iodine (I). Single fabricated DSSC cell shown better performance experimentally in terms of efficiency and fill factor. Therefore, depending on the performance of single DSSC, two DSSC were connected in series. The electrical conduction mechanism of the fabricated DSSC is studied at 50 lux experimentally and was also tested with cascaded series cell connection. The improved efficiency and good fill factor in two series connected DSSC exposes towards fabrication of a solar panel at a large scale.

\section{References}

[1]. Michael Gratzel, "Review: Dye-sensitized solar cells", Journal of Photochemistry and Photobiology C: Photochemistry Reviews, Vol.4, pp.145-153, 2003. 
[2]. Michael Gratzel, "Conversion of sunlight to electric power by nanocrystalline dyesensitized solar cells", Journal of Photochemistry and Photobiology A: Chemistry, Vol. 164, pp.3-14, 2004.

[3]. Bin Li, Liduo Wang, Bonan Kang, Peng Wang, Yong Qiu, "Review of recent progress in solid-state dye-sensitized solar cells", Solar Energy Materials \& Solar Cells, Vol. 90, pp.549-573,2006.

[4]. Fan-Tai Kong, Song-Yuan Dai, and Kong-Jia Wang, "Review of recent progress in dyesensitized solar cells", Advances in OptoElectronics-Hindawi Publishing Corporation, pp.1-13, 2007.

[5]. Di Wei, "Dye sensitized solar cells", International Journal of Molecular Sciences, Vol.11, pp.1103-1113, 2010.

[6]. Ajay Jena, Shyama Prasad Mohanty, Pragyensh Kumar, Johns Naduvuth, Vivekanand Gondane, P. Lekha, Jaykrushna Das et al., "Dye sensitized solar cells", Trans. Ind. Ceram. Soc., Vol.71, No.1, pp.1-16, 2012.

[7]. Umer Mehmood, Saleem-ur Rahman, Khalil Harrabi, Ibnelwaleed A. Hussein and B.V.S.Reddy, "Recent advances in dye sensitized solar cells", Advances in Materials Science and Engineering-Hindawi Publishing Corporation, pp.1-12,2014.

[8]. Akira Fujishima, Tata N. Rao, Donald A. Tryk, "Titanium dioxide photocatalysis", Journal of Photochemistry and Photobiology C: Photochemistry Reviews, Vol.1, pp.121,2000.

[9]. Prakash T., "Review on Nanostructured Semiconductors for Dye Sensitized Solar Cells", Electronic Materials Letters, Vol.8, No.3, pp.231-243, 2012.

[10]. Regan O. and Gratzel M., "A low-cost, high-efficiency solar cell based on dye-sensitized colloidal $\mathrm{TiO}_{2}$ films", Nature, Vol.353, pp.737-740, 1991.

[11]. Ahmed A. El Tayyan., "Dye sensitized solar cell: parameters calculation and model integration", Journal of Electron Devices, Vol.11, pp.616-624, 2011.

[12]. Gratzel M., "Photoelectrochemical cells", Nature, Vol.414, pp.338-344, 2001.

[13]. Haque S.A., Emilio Palomares, Upadhyaya HM, Lucy Otley, Robert J. Potter, Andrew B. Holmes et al., "Flexible dye-sensitized nanocrystalline semiconductor solar cells", Chemical Communications, pp.3008-3009,2003.

[14]. Tsutomu Miyasaka, Yujiro Kijitori, Takurou N. Murakami, Mitsuhiro Kimura, Sadao Uegusa, "Efficient nonsintering type dye-sensitized photocells based on electrophoretically deposited TiO2 layers", Chemistry Letters, Vol.31, pp.1250-1251, 2002.

[15]. Taher M. El-Agez, Sofyan A. Taya, Kamal S. Elrefi, Monzir S. Abdel-Latif, "Dyesensitized solar cells using some organic dyes as photosensitizers", Optica Applicata, Vol. XLIV, No.2, pp.345-351, 2014.

[16]. Lalitha Priya R., Salim Subi, Vaishnu B. and K.R.M. Vijaya Chandrakala, "Study on characterization of river sand as heat storage medium", Indian Journal of Science and Technology, Vol.9, No.30, pp.1-5 August 2016.

[17]. M.P. Pranitha and K.R.M. Vijaya Chandrakala, "Optimal capacitor placement based improved reliability assessment of a distribution system", Indian Journal of Science and Technology, Vol.9, No.30, pp.1-7, August 2016. 


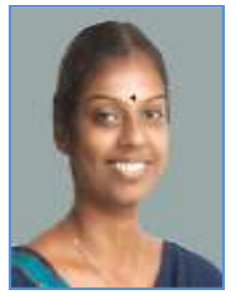

K.R.M. Vijaya Chandrakala born at Bangalore, India. She obtained her Ph.D., in power system control from Anna University, Chennai, India. Currently, she is working at Amrita School of Engineering, Amrita Vishwa Vidyapeetham, Ettimadai, Coimbatore, India in EEE Department as Assistant Professor (Selection Grade). Her area of interest is load frequency control, soft computing techniques and micro grid.

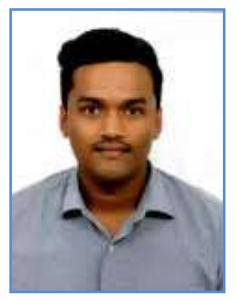

K. Ravi Teja completed his B.Tech., EEE from Amrita School of Engineering, Amrita Vishwa Vidyapeetham, Ettimadai, Coimbatore, India. Currently he is working at Tata Consultancy Services, Chennai, India from September 2015 onwards. His area of interest is power system and renewable energy.

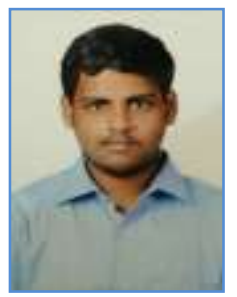

N. Sandeep Kumar completed his B.Tech., EEE from Amrita School of Engineering, Amrita Vishwa Vidyapeetham, Ettimadai, Coimbatore, India. Currently he is working at Tata Consultancy Services, Chennai, India from November 2015 onwards. His area of interest is utilization of energy, power system protection and renewable energy.

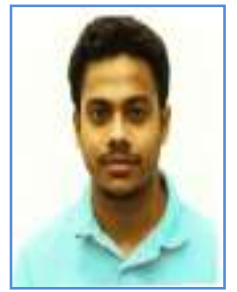

P. Vivek Phani Raghavendra completed his B.Tech., EEE from Amrita School of Engineering, Amrita Vishwa Vidyapeetham, Ettimadai, Coimbatore, India. Currently he is pursuing Masters in Information Technology at the University of Tampa. His area of interest is renewable energy sources and machines.

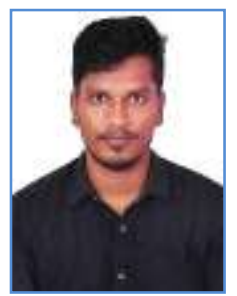

LNV Sai Bhaskar Majji completed his B.Tech., EEE from Amrita School of Engineering, Amrita Vishwa Vidyapeetham, Ettimadai, Coimbatore, India. Currently he is working at Tata Consultancy Services, Hyderabad, India from September 2015 onwards. His area of interest is in machines, renewable sources and power systems. 